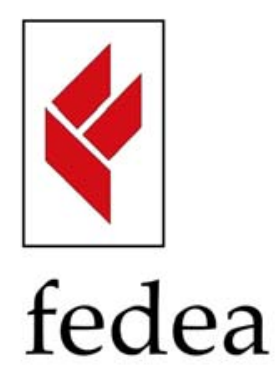

Fundación de

Estudios de

Economía Aplicada

\title{
An Integrated Approach to Simulate the Impacts of Carbon Emissions Trading Schemes
}

by

Xavier Labandeira *

Pedro Linares**

Miguel Rodríguez *

Documento de Trabajo 2009-29

\section{Economía del Cambio Climático \\ FEDEA - Iberdrola}

September 2009

FEDEA and rede, University of Vigo. Facultade de CC. Económicas, Campus As Lagoas, E 36310 Vigo, Spain._Corresponding author: miguel.r@uvigo.es

** Universidad Pontificia Comillas, Harvard Kennedy School and FEDEA. C/ Alberto Aguilera 23, E 28015 Madrid, Spain.

Los Documentos de Trabajo se distribuyen gratuitamente a las Universidades e Instituciones de Investigación que lo solicitan. No obstante están disponibles en texto completo a través de Internet: $h t t p: / / w w w . f e d e a . e s$.

These Working Paper are distributed free of charge to University Department and other Research Centres. They are also available through Internet: $h t t p: / / w w w . f e d e a . e s$.

ISSN:1696-750X 


\title{
An Integrated Approach to Simulate the Impacts of Carbon Emissions Trading Schemes
}

\author{
Xavier Labandeira ${ }^{*}$ Pedro Linares ${ }^{* *}$ and Miguel Rodríguez ${ }^{*}$
}

The present paper aims to reliably depict the impact of the European Union Emissions Trading Scheme (EU ETS) on Spain under different assumptions about the industries involved. Prior analyses, based either on highly aggregated macroeconomic or specific electricity industry models, have been limited in degree of detail or scope. Two types of modeling were combined in the present study: general equilibrium was used to assess the impact on different industries and to explain cross-industry changes, and partial equilibrium to suitably model the complex and crucial electricity system. Combining and interrelating these two models yields the effects on price, carbon dioxide $\left(\mathrm{CO}_{2}\right)$ emissions and distributional patterns in Spain of both the current policy and an alternative in which all industries take part in the EU ETS. Since Spain is a key participant in this scheme, the conclusions and policy implications stemming from this paper are relevant to and useful for post-Kyoto arrangements.

\footnotetext{
* FEDEA and rede, University of Vigo. Facultade de CC. Económicas, Campus As Lagoas, E 36310 Vigo, Spain. Corresponding author: miguel.r@uvigo.es.

** Universidad Pontificia Comillas, Harvard Kennedy School and FEDEA. C/ Alberto Aguilera 23, E 28015 Madrid, Spain.
}

\footnotetext{
The authors benefited from comments by two reviewers. Funding for this study has been provided by the BBVA Foundation and the Spanish Ministry of Science and Innovation and ERDF (Project SEJ2006-12939). The authors bear full responsibility for any errors in or omissions from this paper.
} 


\section{INTRODUCTION}

As the current debate in Europe and the US clearly shows, the economic implications of climate policies are broad and complex, with many aspects to be considered, from setting the right emissions targets to defining the instruments to reach them.

A consensus around the policy itself seems to have been reached with the establishment of carbon emissions trading. This approach was pioneered by the European Commission under Directive 2003/87/EC, which instituted the European Union Emissions Trading Scheme (EU ETS). The EU ETS is generally considered to be a first step in the right direction, with some positive aspects and others calling for further improvement (Ellerman and Joskow, 2008). The most relevant of the latter include the way emission allowances are allocated and the industrial sectors that should be included in the scheme. Under the current policy, allowances are grandfathered to the industries affected. This is a controversial measure, given its distributional impact and the impossibility of improving its economic efficiency by recycling the revenues that might be obtained if the allowances were auctioned (double dividend). Furthermore, the scope of this directive is limited, since it only affects a subset of greenhouse gas (GHG) emitters and therefore only covers about half of European GHG emissions. This has been justified by a number of considerations, from the avoidance of high transaction costs to the minimization of monitoring costs. It may, however, also entail substantial inefficiencies, for it fails to benefit from all the possible sources of mitigation, may induce emissions leakage from regulated sectors to non-regulated ones, and introduces adverse distributive effects.

Consequently, many relevant issues have yet to be analyzed from the economic standpoint, particularly since the European Commission has recently put forward a draft for a new directive (European Commission, 2009). This new regulation includes an auction system for most of the allowances (subject to international competitiveness concerns) and the inclusion of further industrial sectors in the EU ETS. The so-called Climate Package, within which this new proposal is framed, also envisages setting mandatory national limits for non- EU ETS industries, an issue not previously covered, 
probably because it was included in the Kyoto Protocol targets. The appearance of proposals for similar schemes in the US and Australia lends even more relevance to the need for careful research into these subjects.

This paper mainly aims to address one such issue: the enlargement of the EU ETS to all industries and sectors, to explore the added burden generated by excluding non-manufacturing industries from trading. To that end, the impact of the EU ETS on the Spanish economy is assessed under two scenarios: the current scheme and one in which all industries are allowed to trade. This issue was first broached at the European level by Böhringer et al. (2005), who proposed a simulation based on a computable general equilibrium (CGE) model. Pizer et al (2006) and Edmonds et al (2006) have also looked at this issue for the US, again using basically CGE models. Full representation of all the effects would, however, require more complex and detailed economic modeling, particularly for the electricity industry, which is a key player in the EU ETS.

This paper, then, deploys a hybrid methodology that integrates a CGE (top-down) and an electricity industry (bottom-up) model to enhance the separate explanatory power of each. The current state of the art on the integration of top-down and bottom-up models is described in Section 2, while Section 3 presents the methodology proposed in this paper. Section 4 illustrates its application in the assessment of the impact of the EU ETS on the Spanish economy. Finally, Section 5 sets out a number of conclusions and recommendations for policy makers.

\section{INTEGRATING BOTTOM-UP AND TOP-DOWN APPROACHES}

Taken separately, top-down (CGE) and bottom-up (partial equilibrium, engineering) models are not well suited to the analysis of such a complex issue as the impact of the EU ETS on national economies. Given their microeconomic basis, general equilibrium models can analyze the impact of different policies on the economy as a whole and the interactions between agents and sectors. Although they are very powerful tools for assessing the efficiency and distributive effects of public policies 
(Shoven and Whalley, 1992), their major drawback is the high level of aggregation required, which prevents them from dealing in detail with industries that may be highly relevant to these policies. A case in point is the electricity industry, a key player in the EU ETS, which under a CGE approach would probably be represented with a significant loss of detail, or even incorrectly for reasons explained below. Yet the use of bottom-up or engineering models alone, which may represent the electricity industry more adequately, cannot be used to assess the impact of the EU ETS on the economy as a whole, for they fail to take account of the interaction with other energy inputs that may affect the demand for electricity, and to cover the full scope of the EU ETS.

The electricity market is difficult to represent in top-down models for a number of reasons: electric power cannot be stored, the demand for electricity changes during the day and power may be generated by a number of complementary technologies. Moreover, since power plant dispatching is a discrete decision, the electricity supply function is not smooth and substitutability with respect to different segments of the load duration curve is imperfect. The ultimate consequence is that most CGE models are unable to correctly represent marginal prices in electricity markets. Inasmuch as the electric power industry is liberalized in most European countries, where the basis is the marginal price, this is a highly relevant issue. A final problem is that the CES (constant elasticity of substitution) functions usually modeled in top-down approaches conserve monetary values, but not the physical energy flows that would be required for the electricity industry (Sue Wing, 2006).

Therefore, if the electricity industry is to be modeled in detail, top-down models must be enhanced to account for this complexity. Böhringer (1998), for example, showed that substituting six engineering-based descriptions of electric power generation for a single CES approximation significantly impacts policy analysis. This would be unnecessary, of course, where the weight of the electricity industry is insignificant for the policy studied, as in Hogan and Manne’s (1977) elephant and rabbit stew metaphor. In that case, the non-energy production function of top-down models might be kept constant. Such an assumption would appear to be unrealistic when assessing climate policies, however, given the very relevant role of the energy industry (Ghersi and Hourcade, 2006), which accounts for nearly 50\% of 
the carbon emissions included in the EU ETS. A detailed representation of the industry is therefore warranted. A reasonable estimate of the impact of the policy reviewed in this paper would appear to necessitate an integrated approach, including both types of models. Such integration may be conducted in essentially three ways (Böhringer and Rutherford, 2008).

In one, a reduced version of one of the models is incorporated into the other. The two obvious alternatives in this case are to include a reduced form of a bottom-up into a top-down model, or viceversa. An example of the first can be found in Bosetti et al. (2006), and of the second in Rivers and Jaccard (2005) and Manne et al. (2006). The latter option generally entails aggregating the entire economy into a single industry, which indisputably involves a significant reduction in the level of detail provided by the model ${ }^{1}$. But the first option is not error-free either, of course. Internal consistency calls for careful calibration of the top-down model. Estimating substitution elasticities from historic data, for instance, affords no guarantee that the values will remain valid. Pizer et al.(2006) attempted to solve this problem by using bottom-up models to parameterize the reduced-form version of the energy industry included in the top-down model. Such an approach cannot be used to obtain a detailed analysis of the impact of the policy studied on the electricity industry either, however.

The second approach is to integrate full versions of both models into a single entity. This is what Hourcade et al.(2006) call the holy grail: "a composite hybrid model that includes all the major theoretical and structural characteristics of the most advanced top-down models with the major characteristics of the most advanced bottom-up models, with technological detail in all sectors and behavioral parameters estimated from research.” Although such a model would pose huge challenges in terms of consistency, complexity and empirical estimation (Hourcade et al., 2006), some steps in that direction have already been taken. Böhringer (1998) first proposed a fully-integrated hybrid model in which the top-down model is formulated as a mixed complementarity problem (MCP) whereby mathematical programming constraints can be included to represent energy technology options. This

\footnotetext{
${ }^{1}$ Which in turn means lower heterogeneity of industries and therefore reduced substitution opportunities and higher costs from any simulated policy.
} 
method, which has been applied to analyze renewable energy policies (Böhringer and Loschel, 2006), was further described by Böhringer and Rutherford (2008). It does not solve the problems of consistency between engineering and macroeconomic data, however. Sue Wing (2008) proposed a method for reconciling these inconsistencies and introducing bottom-up data into a hybrid model through Leontief production functions, and applied it to climate policy modeling. The chief problem in this approach is the algebraic complexity and dimensionality involved, which severely limits the real-world application of such models (Böhringer and Rutherford, 2007).

Indeed, most of the hybrid models described above are unable to accommodate multiple periods for electric power generation, a major feature of electricity markets and the one on which the choice of technology and its operation is largely based. McFarland et al. (2004) attempted to take this into consideration by converting bottom-up engineering costs into factors of production, and specifying elasticities of substitution between factors as well as costs relative to existing technologies for different load levels. The number of load levels that can be specified under this methodology is clearly limited, unfortunately.

A third and final option is to soft-link the models. This would entail allowing for communication between two separate entities (the top-down and bottom-up models) in an attempt to find convergent results. The inconsistencies in behavioral assumptions and accounting concepts are much more significant in this than in previous approaches, and serious problems are certain to be encountered around the convergence of the solution algorithm (Böhringer and Rutherford, 2007). Nonetheless, in light of the drawbacks to the other two approaches, this was found to be the best compromise solution for the present study because it provides the highest degree of detail without forfeiting computational feasibility.

A number of authors have implemented this approach. Schafer and Jacoby (2006) linked a bottom-up (MARKAL) to a top-down (EPPA) model via an iterative algorithm. The top-down model fed input prices and demand levels into the bottom-up model, which delivered elasticities of substitution. Yet this approximation has been rightly criticized by Böhringer and Rutherford (2007) as likely to fail because the linear profit-maximizing program (MARKAL, in this case) takes no account of market 
demand response to changes in energy prices. These authors proposed a decomposition technique instead as the iterative algorithm for convergence, formulating the top-down model as an MCP and the bottom-up model as a quadratic program. First they solved the top-down model, assuming certain energy supply and input values. The prices and demand functions for the energy industry outputs resulting from the topdown model were then fed into the bottom-up model. The solution for the energy industry sub-model was based on a locally calibrated set of demand functions for industry outputs. Iterative (Jacobi) algorithm convergence, however, requires a small decomposed energy industry relative to the rest of the economy, which is scarcely realistic in the context of the EU ETS.

The approach initially adopted in this paper was similar to Schafer and Jacoby’s (2006), but to obviate the shortcoming described above, instead of a linear program, an MCP able to incorporate a priceresponsive demand function was used as the bottom-up model. This approach is likewise similar to the one proposed by Böhringer and Rutherford (2007), although with lesser model complexity (at the expense of convergence power). The specific details of the approach presented in the paper are explained in the following section.

\section{INTEGRATING PARTIAL AND GENERAL EQUILIBRIUM MODELS FOR SPAIN}

\subsection{The general equilibrium model}

A static computable general equilibrium (CGE) model was used to evaluate the overall effects of the EU ETS on the Spanish economy ${ }^{2}$. Industries and institutions were disaggregated in accordance with the information available, an important step for considering the variations in energy consumption by different agents into consideration. The energy industry itself was disaggregated to the deepest possible level of detail in light of the variety of services it provides (intermediate inputs for electric power

\footnotetext{
${ }^{2}$ See Labandeira et al. (2009) for a more technical and detailed description of the CGE model.
} 
generation, lighting, heating, transport services, and so on) and the dissimilarity of their environmental effects.

The model therefore includes 17 price-taking productive (and commodity) industries that minimize cost, subject to constant returns to scale. The production function, in turn, is a succession of nested constant elasticity of substitution (CES) functions. As is normally the case in CGE models, total production in industry $i$ is a combination, through a Leontief function, of intermediate inputs and a composite good consisting of added value (capital and labor) and energy. Energy, in turn, is a combination of electric power and primary energy products, which are themselves a composite good made up of coal and hydrocarbons. Finally, hydrocarbons are also a composite good comprising natural gas and refined oil products.

The Armington approach was adopted to model the international trade of goods, regarding imported products to be imperfect substitutes for national production. Therefore, the total supply of goods and services in the economy is the output from different sources combined by means of a CES function. Profit maximization by industry, determined using a constant elasticity of transformation (CET) function $^{3}$, allocates the supply of goods and services to the export market and domestic consumption.

Since the Spanish economy is small and most commodity trading is with countries in the European Monetary Union (EMU), the exchange rate is fixed and all agents face exogenous world prices $^{4}$. Capital supply is assumed to be inelastic (exogenously distributed among institutions), perfectly mobile across industries, but immobile internationally. The model assumes a competitive labor market and therefore an economy with no involuntary unemployment. Labor supplied by households to maximize utility is also perfectly mobile across industries but immobile internationally. The public sector collects both direct (on income and labor) and indirect (on production and consumption) taxes. Endowment of capital for the government, transfers with other institutions and the public deficit are exogenous variables. The consumption of goods and services by the government is determined by a

\footnotetext{
${ }^{3}$ For more on this, see Shoven and Whalley (1992).

${ }^{4}$ The policy simulated is assumed to have no significant impact on the Euro exchange rate, for it has a relatively small impact on the Spanish economy and Spain's major business partners are in the EMU.
} 
Cobb-Douglas function. Therefore, total public spending, capital income and tax revenues must be balanced to meet the public budget constraint.

The representative household has a fixed endowment of time which is divided between leisure and supply of labor. It maximizes utility, which is a function of leisure, and a composite good consisting of goods and savings, subject to the budget constraint. Following Böhringer et al. (1997), consumers are assumed to have a constant marginal propensity to save, which is a function of disposable income. The latter is equal to the sum of capital income plus labor income and transfers minus the income tax. Consumption of goods and services is defined by a nested CES function, with special attention paid to the consumption of energy goods. An important contribution of this CGE model is indeed the distinction, common in microeconomic models, among energy for the home, private transport and other products.

The CGE represents a structural model based on the Walrasian concept of equilibrium. Therefore, for each simulated policy, the model should find a set of prices and quantities so that all markets (capital ${ }^{5}$, labor and commodities) are cleared up. Total savings in the economy are defined endogenously and are equal to the sum of all institutions' savings. Macroeconomic equilibrium is determined by the economy’s exogenous financing capacity/need with respect to the foreign sector, i.e. the difference between national savings, public deficit and national investment. Investment is a good aggregated by means of a Leontief function that includes the commodities used in gross capital formation. International prices, transfers between the foreign sector and other institutions and the consumption of goods and services in Spain by foreigners are exogenous variables. Therefore, exports and imports must be balanced to satisfy the macroeconomic closure rule.

An important consequence of the application of a public policy on energy domain efficiency is related to the industry's environmental impact. The model therefore includes one of the chief environmental indicators too: the energy-specific carbon dioxide emissions $\left(\mathrm{CO}_{2}\right)$ discharged into the atmosphere by each industry. Emissions are generated in fossil fuel combustion only, and the relationship

\footnotetext{
${ }^{5}$ The total supply of capital in the economy is not adjusted quantitatively because the capital endowment between institutions is an exogenous variable. The changes only affect the use of capital by industry. The equilibrium condition is attained through changes in the price of capital services.
} 
between fossil fuel consumption in physical units and emissions is defined by specific conversion factors for each one (coal, refined oil products and natural gas).

Policy analysis based on the above model calls for calculating a national accounting matrix for the Spanish economy (NAM-95) structured in accordance with the European System of Accounts (ESA95). The matrix includes 17 price-taking productive (and commodity) industries and three institutions (representative household, public sector and foreign sector). The point of departure to calculate NAM-95 was the national accounts for $1995^{6}$, enlarging the database to include environmental data relating fossil fuel consumption to emissions for each industry and institution. Unfortunately, environmental statistics disaggregated to the level needed for this study are not available, and so had to be estimated from IEA (1998) and INE (2002a, 2002b).

The NAM-95 information could be used to obtain a number of model parameters by calibration: effective tax rates, technical coefficients in the production functions and parameters in the utility function. The criterion for calibrating the model was the well known premise that CGE must be able to replicate the information contained in NAM-95 as an optimum equilibrium, which would subsequently be used as a benchmark $^{7}$.

Certain parameters, such as elasticities of substitution, were not calibrated but taken from the literature. For instance, the wage elasticity of labor supply used was 0.4 , as estimated for Spain by Labeaga and Sanz (2001). The Ballard et al. (1985) procedure was used to gauge the elasticity of labor supply, assuming that leisure represents one third of the effective working hours specified in the benchmark (Parry et al., 1999). A sensitivity analysis consisting in increasing and reducing labor elasticity by $50 \%$ showed that the CGE results were robust.

\footnotetext{
${ }^{6}$ Based on a NAM published by Fernández and Manrique (2006). The Spanish national accounts for 1995 are structured in accordance with the European System of Accounts (ESA-95).

${ }^{7}$ The general equilibrium model was programmed using GAMS/MPSGE and calibrated with the method proposed in Rutherford (1999), using the PATH solver-algorithm.
} 


\subsection{The electricity sector model}

The bottom-up model used in this simulation is an oligopolistic model for the Spanish electricity sector developed by Linares et al. (2008a). Although dynamic, the model is used here for static analysis only. The model can also represent an endogenous carbon allowance market (see e.g. Linares et al., 2006). For the purposes of integration, however, the price given by the top-down model is used. Conjectural variation is assumed in the model's representation of electric power market agents (Vives, 1999). Consequently, the structure of the model used in this paper involves a number of simultaneous optimizations (the maximization of each firm's profits subject to its specific technical constraints). These optimization problems are linked through the market price resulting from the interaction among all the players. Consequently, the market equilibrium problem can be stated in terms of an LCP scheme by setting the first order Karush-Kuhn-Tucker optimality conditions to the set of maximization programs.

This structure allows for a realistic representation of the Spanish electricity sector because the generation system is modeled to deeper detail, thus providing useful information on the impact of the policies studied on utilities and technologies ${ }^{8}$.

\subsection{Model integration}

As mentioned earlier, an accurate assessment of the impact of the EU ETS on the Spanish economy calls for integrating the two types of models. The iterative approach adopted here establishes a bidirectional flow between the two. Iteration is begun by using the CGE model to simulate the scenarios defined. This yields changes in quantities and prices in the Spanish economy for the sectors studied. Since a constraint for carbon emissions is included, a price for the carbon emission allowance is also generated. These new quantities and prices, essentially level of electricity demand, energy input (coal, gas and oil)

\footnotetext{
${ }^{8}$ For a detailed discussion of the mathematical structure of the model see Linares et al. (2006; 2008a).
} 
prices and the emission allowance price, are then fed into the electricity sector model. Since the CGE produces relative changes only, they must be applied to the original electricity sector demand and price levels.

Running the electricity sector model with these new demand and price levels yields new values for the electric power price, level of fuel use and the sector's carbon emissions. The straightforward approach would be to enter these new levels as constraints and re-run the CGE model. However, due to the way the model is programmed, this approach is not feasible and an alternative must be deployed: the CGE model is recalibrated by entering a series of productivity shocks in the fuels to replicate electricity sector results. With this procedure, the productive structure of the electricity sector in the CGE bears a closer resemblance to the structure predicted by the electricity sector model. The original elasticities of substitution are subsequently modified so the prices predicted by the electricity sector model are reproduced by the CGE model as an equilibrium solution. As a result of this recalibration and modification procedure, the CGE and electricity sector models use consistent electric power-related data.

The CGE model is then re-run and the relative changes in electric power demand, fuel and allowance prices are re-entered into the electricity sector model, which computes the changes in electric power prices, fuel consumption and carbon emissions. These steps are repeated until a reasonable degree of convergence is reached. A diagram of the process is shown in Figure 1.

While the process works, as the results show, it has some drawbacks. It is time-consuming, since several iterations may have to be run before attaining a reasonable degree of convergence. Moreover, the approach used does not allow for obtaining a rigorous proof of convergence, and in fact only limited convergence could be obtained for the scenarios - although this convergence was obtained for all scenarios and sensitivity analyses, thus making the methodology robust enough for our needs. In addition, since the precision of most modeling results is severely compromised by the simplifying assumptions made, the ranges obtained here were deemed to be satisfactory to illustrate the need for integrated approaches, and provide good approximations of the expected impact. Research is ongoing to solve these methodological limitations. 


\section{Figure 1. Interaction between the CGE and electricity sector models}

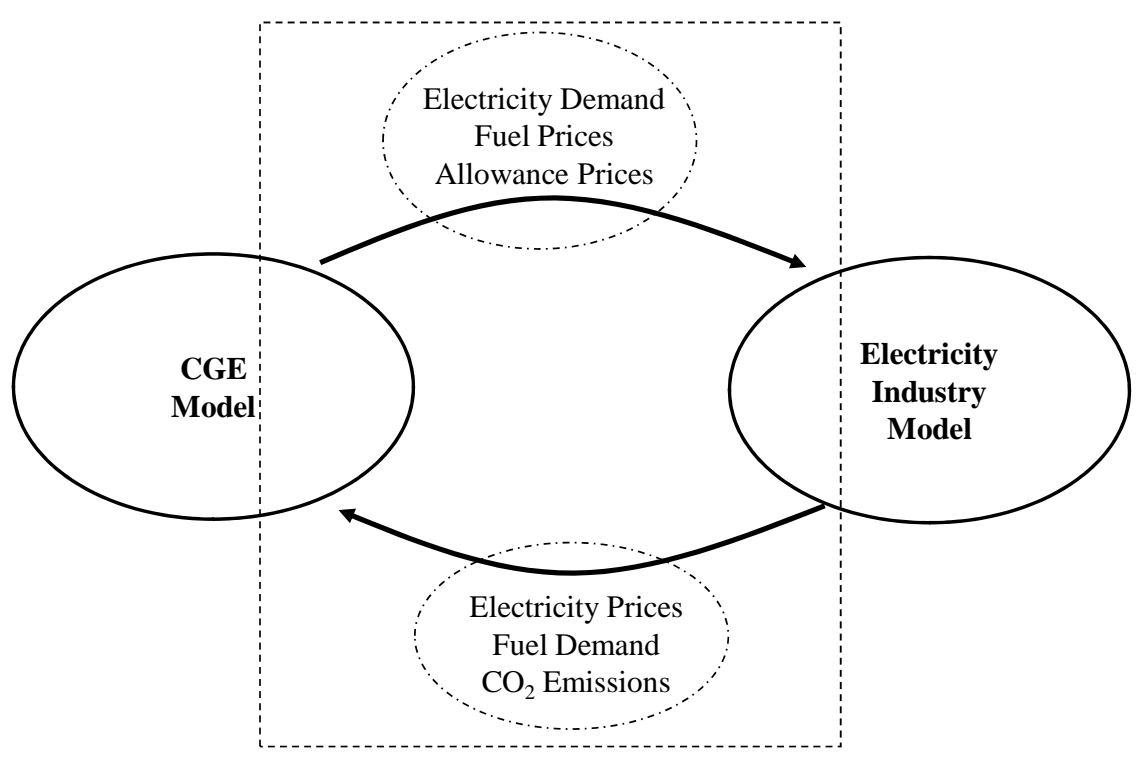

Source: The authors

\section{RESULTS}

\subsection{Definition of scenarios}

Since 2005 Spanish $\mathrm{CO}_{2}$ emissions have been approximately 50\% higher than they were in 1990 .

If no additional action is taken, the government estimates that the rise over the 1990 figure will come to 50 to $55 \%$ by the end of the Kyoto compliance period. Consequently, the current Spanish National Allocation Plan of GHG emissions (NAP) establishes the need for domestic reductions of 16\% by 2012, i.e., the difference between the estimated increase in emissions and the amount allocated to Spain in the 
burden sharing agreement (15\%) plus the estimated absorption by domestic forestation projects (2\%) and the use of other (project-based) Kyoto Protocol mechanisms (20\%). Hence, the volume of emission reductions required in the present NAP is large enough to make Spain an interesting example of intense and speedy climate change policy, with obvious consequences in terms of efficiency and distributive impacts.

The simulations discussed below assume an isolated Spanish market which, in light of the size of the reductions sought in comparison to other European market countries, will unquestionably give rise to a higher allowance price (for which reason they should be taken as upper ranges). Nonetheless, since the productive structure of the Spanish electricity sector is not materially different from the structures in place in the rest of Europe, the final results may be regarded to be a reasonable approximation of what might be expected from a Europe-wide analysis. The 2008 Spanish electricity mix is basically 10-15\% hydro (depending on rainfall), 20\% nuclear, 15\% coal (both imported and domestic, the latter including black and brown lignite), and 30\% combined cycles. Renewables (not including hydro) contribute with $15 \%$ of the total demand, and are expected to grow up to $40 \%$. The market is a rather concentrated one, with two large firms covering a large part of the generation market and only four more small firms with some generation capacity, which cover the rest of the market. More information about the Spanish electricity system and its expected evolution may be found in Linares et al (2008b).

The simulations likewise assume that the non-EU ETS industries are not subject to supplementary environmental policies (such as additional command and control regulations, environmental taxes and so on), which has been the case in Spain to date.

The first simulation discussed is the current scenario, with cost-free allocation of allowances as provided in Directive 2003/87/EC and the Spanish NAP ${ }^{9}$. The second simulation, called the expanded scenario, broadens the scope of the emissions trading directive to all industries, leaving only households outside the market.

\footnotetext{
${ }^{9}$ Neither paper nor pulp are included for want of data. This has no significant impact on the results, however, for this industry’s $\mathrm{CO}_{2}$ emissions are scantly relevant (1.3\% of the total).
} 
The aim of the second scenario is to analyze the efficiency costs generated by the limitations of the EU ETS discussed in the introduction. This is useful in economies with many mobile and stationary non-EU ETS emitters (road transport, small enterprise, agriculture and so on), which together account for a substantial percentage of total emissions and that in some cases may have low abatement $\operatorname{costs}^{10}$. Another reason for exploring this scenario is to compare the distributive patterns (in macroeconomic terms) of different policies that aim to reach the same environmental target.

There may be diverse justifications for such a limited scope of the the EU ETS in light of the difficulties inherent in enlarging the market to all actors due to high administrative (regulatory) costs involved in supervision and enforcement, and to high (private) compliance costs for small players. In any event, the enlarged market simulation could be interpreted as the introduction of supplementary (costeffective) policies in industries and sectors not subject to the EU ETS, most likely in the form of environmental taxes on $\mathrm{CO}_{2}$ emissions.

\subsection{Comparison between CGE-only and integrated results}

As noted earlier, the reason for adopting the integrated approach discussed here is that it would be expected to yield more reliable results than a CGE-only assessment. Consequently, a discussion of the differences between the two approaches for the first scenario considered (the current scenario) and their respective reliability would appear to be in order.

Be it said that the results obtained with integration are given as ranges, for the iterative procedure did not yield full convergence as indicated before. Nonetheless, the ranges are small enough to illustrate the relevance of such an integrated approach, and the resulting approximations of the impact to be expected under different scenarios are valid for the purposes of policy making. In any case, a satisfactory

\footnotetext{
${ }^{10}$ Over $50 \%$ in all EU countries. In Spain, the transport sector alone generates approximately $25 \%$ of total $\mathrm{CO}_{2}$ emissions, with a rise of 60\% in its carbon figures between 1990 and 2002.
} 
degree of convergence was attained for all scenarios, which shows the robustness of the method proposed.

Table 1 shows that electric power prices rise more under the integrated approach, a result that is fully consistent with the limited ability of CGE models to adequately represent power market marginal prices and load levels. Indeed, the change in electricity prices under the CGE-only approach is probably too small in comparison to the current situation, whereas the result yielded by the integrated approach is more in line with reality ${ }^{11}$ and with other model predictions (see, e.g., Linares et al., 2006). Of course these changes in the electricity sector drive impacts on GDP and welfare, since electric power becomes more expensive compared to other energy vectors..

Table 1. Results with and without integration for the current scenario

\begin{tabular}{|l|c|c|}
\hline & $\begin{array}{c}\text { CGE alone without } \\
\text { integration }\end{array}$ & $\begin{array}{c}\text { Integrated modeling } \\
\text { framework }\end{array}$ \\
\hline Price of electric power & $+8.6 \%$ & $(+17.0 \%,+21.5 \%)$ \\
\hline Gross Domestic Product (GDP) & $-0.7 \%$ & $-1.0 \%$ \\
\hline Welfare & $-0.3 \%$ & $-0.5 \%$ \\
\hline Price index (CPI) & $+0.2 \%$ & $+0.2 \%$ \\
\hline
\end{tabular}

Source: The authors

Sectoral distributional impacts for both scenarios, in turn, are illustrated in Figures 2 and 3 (see Table 2 for a description of the different sectors). On the one hand, Figure 2 shows that the integrated approach yields minor relative changes in the metallurgy, mineral product and oil industries, the ones most affected by the changes in electricity prices and consumption (apart from energy sectors), with respect to the CGE-only approach. Besides it presents significant relative changes in the electricity, gas,

\footnotetext{
${ }^{11}$ Electricity prices in Spain increased 7€/MWh in average during the first phase of the EU ETS, for a price of $\mathrm{CO}_{2}$ allowances of $18 € / t$, which is consistent with the carbon price obtained in the CGE. That would mean a $20 \%$ increase for the prices simulated, which is in the range of the results provided by the integrated model and clearly above those provided by the CGE model alone.
} 
construction and coal industries. This is also fairly reasonable because incorporating more detailed electricity sector modeling lowers the impact on coal consumption (which is still required for electric power generation, and generators can recover their costs thanks to higher market prices). It simulates also an increase in gas industry (instead of a fall) and deepens the drops in electric power consumption (as a result of higher prices). As confirmed by Figure 3, the integrated approach narrows the reductions in electricity-related carbon emissions (due to the more preponderant role of coal than in the CGE-only model). Actually Figure 3 shows important divergences among emission outcomes from both modeling approaches which are impelled by the different relative changes in production and consumption.

Table 2. Sectors in the CGE model

\begin{tabular}{|l|r|}
\hline AGRICULTURE (FARM) & Agriculture, livestock, forestry, fishing \\
\hline COAL & Extraction and agglomeration of coals \\
\hline MINING (MINER) & Extraction of metallic, non-metallic (except energy-related) minerals \\
\hline OIL (REFINED) & Refined oil products \\
\hline ELECTRICITY (ELEC) & Electricity production \\
\hline GAS & Natural gas production \\
\hline FOOD & Food and drink \\
\hline MANUFACTURING (MANUF) & Other manufacturing industries \\
\hline CHEMICAL (CHEMIC) & Chemical industries \\
\hline MINING PRODUCTION (MINPROD) & Manufacturing of other non-metallic minerals, recycling \\
\hline METAL & Metallurgy \\
\hline CONSTRUCTION (CONST) & Construction \\
\hline SERVICES 1 (SERV1) & Telecommunications, financial services, real estate, R\&D \\
\hline HOTEL-RESTAURANTS (HOSTEL) & Hotels and restaurants \\
\hline TRANSPORT (HAULAG) & Transport services \\
\hline SERVICES 2 (SERV2) & Education, health, leisure, culture, sports \\
\hline
\end{tabular}

Source: The authors 
Figure 2. CGE-only versus integrated approach. Changes in output for the current scenario

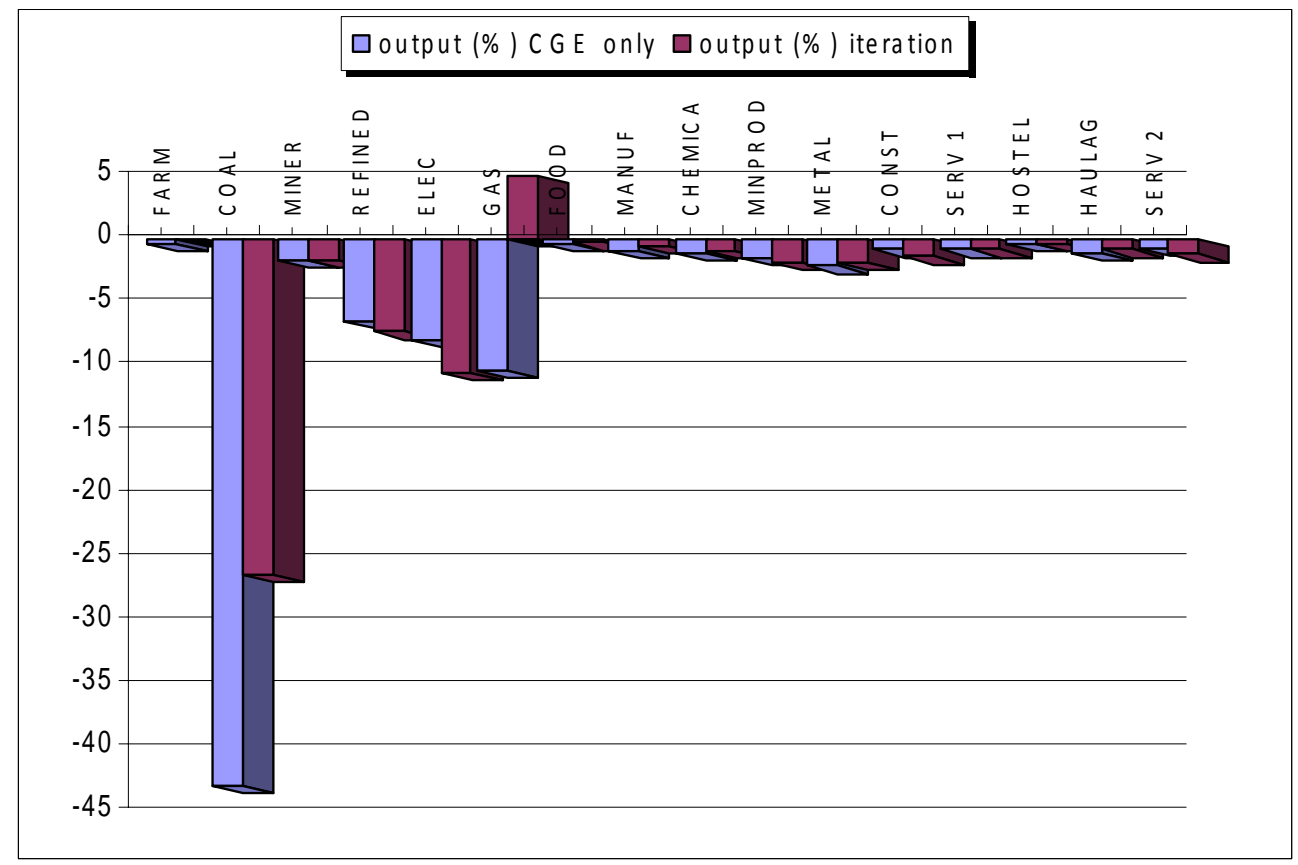

Source: The authors

Figure 3. CGE-only versus current scenario: Changes in $\mathrm{CO}_{2}$ emissions for the current scenario

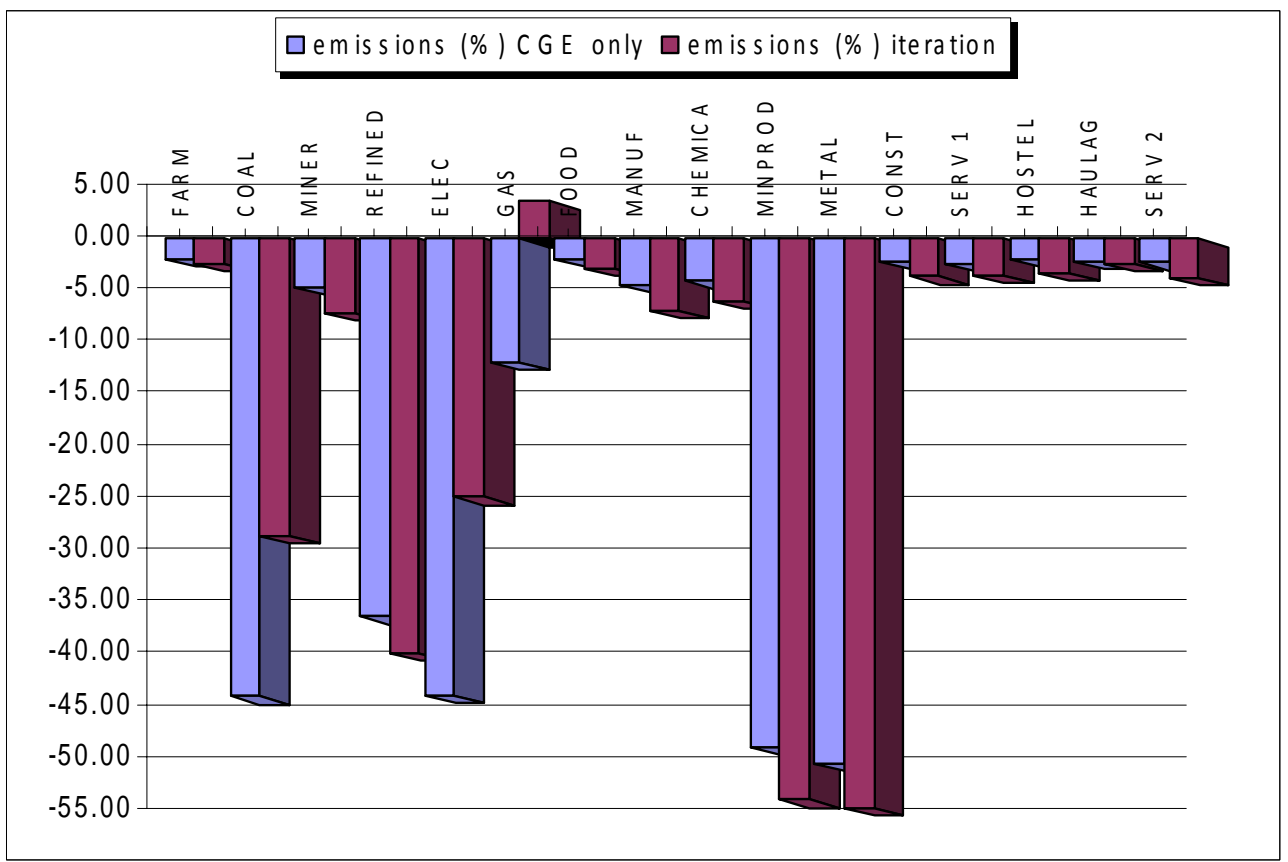

Source: The Authors 


\subsection{Comparison between scenarios}

The integrated results for the two scenarios are given below. These findings can be used to assess the impact of moving from the status quo to a situation in which the EU ETS is enlarged to include all sectors.

\subsubsection{Current scenario}

Under this hypothesis the gross domestic product (GDP) declines by $1 \%$ and prices rise slightly (0.2\%). Consequently, the decline in welfare (measured as equivalent variations with respect to the baseline level) is on the order of $0.5 \%$.

The reform simulated with the integrated methodology brings about the distributive impact by industry presented in Figure 4 (see also Tables 3 and 4). The most significant changes in output are observed in the electricity sector. The overall change in electric power production and consumption by the Spanish economy observed for the current situation is around $-10.5 \%$. Consequently, the electricity sector changes the input mix by reducing coal consumption $(-25.7 \%,-41.2 \%)$ and oil consumption $(-91.9 \%,-97.5 \%)$ which is counterbalanced by a rise in natural gas consumption $(25.8 \%, 33.7 \%)$.

Furthermore there are also significant losses of activity in other industries subject to the EU ETS, such as metallurgy and mineral products, which push down the output in the construction sector through the pressure on prices. Finally, there will be a reduction in mining activities and other industries and services through the general equilibrium effects of the policy reform.

At the same time, the technological circumstances of the electricity sector allow for a substantial reduction of $\mathrm{CO}_{2}$ emissions (-24.8\%, -27.9\%). However, the major impact on $\mathrm{CO}_{2}$ emissions will be on the metallurgy and mineral products. As a result, they become the main source of permits for the electricity sector (as it was the case in the marketplace experience with the EU ETS during the first period 2005-2007). 
Figure 4. Impact on output and emissions by industry in the current scenario

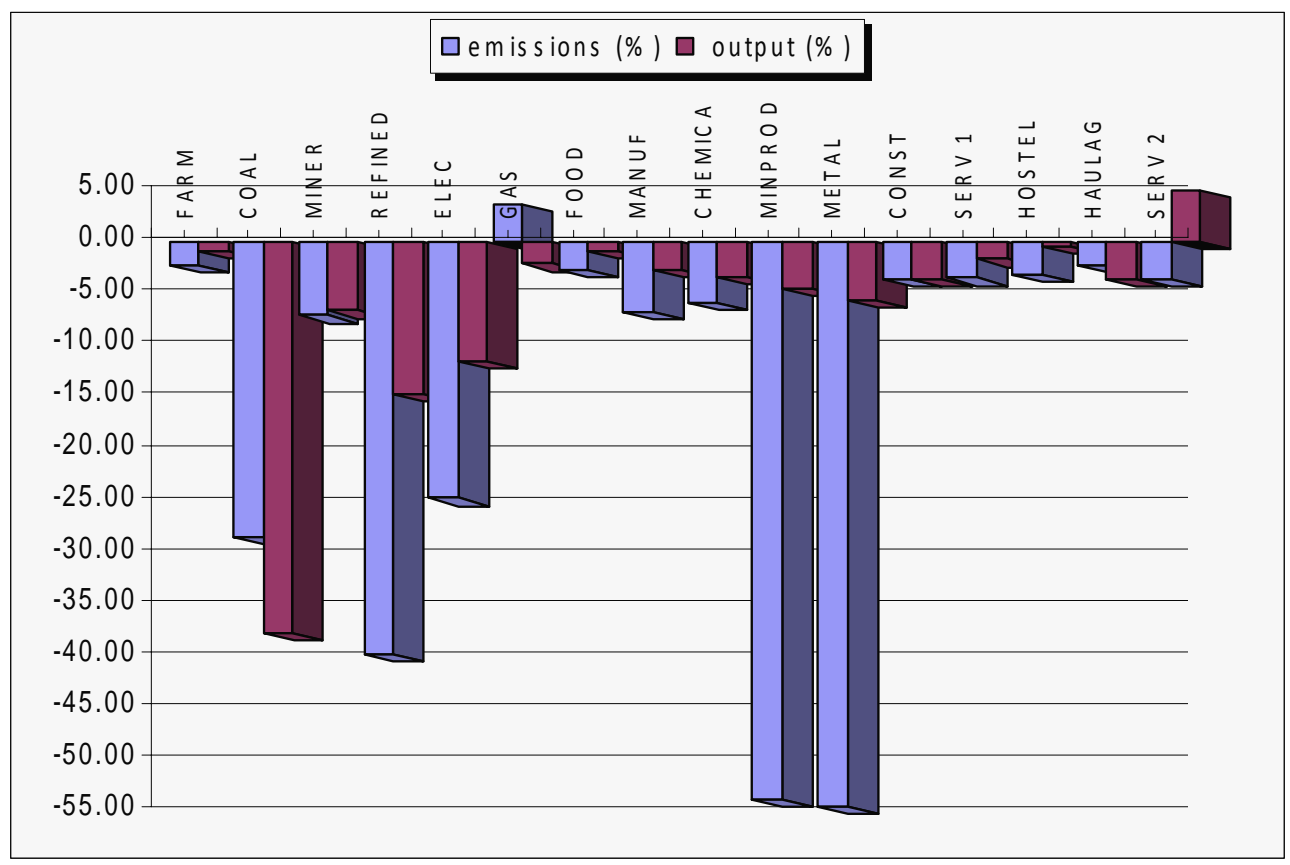

Source: The authors

\subsubsection{Expanded scenario}

With respect to previous findings, there are now improvements in terms of activity as GDP declines by only $0.5 \%$. Nonetheless, both prices $(+0.4 \%)$ and welfare measured as equivalent variations (- 0.8\%) follow a less favorable pattern. That is a consequence of (i) redistributing the abatement effort among a greater number of sectors, thus lowering the macroeconomic costs for the economy, and of (ii) the abatement efforts that are carried out in sectors with a larger weight in the household consumption basket. More specifically, in this scenario return on capital and retribution for labor are reduced by a substantial $1.0 \%$ and $2.5 \%$, respectively.

The change in the price of electricity falls within the $(13.3 \%, 16.1 \%)$ range, lower than in the previous scenario because of the lower carbon price (due in turn to the expanded mitigation options). The estimated change in coal consumption by the electricity industry in this case is $(-40.0 \%,-41.5 \%)$, while 
oil consumption by electric power generators tumbles $(-95.2 \%,-98.6 \%)$. The rise in natural gas consumption by this industry is in the $(17.3 \%, 18.3 \%)$ range.

As a whole, the decline in electric power production and consumption by the Spanish economy comes to $11.6 \%$ (somewhat higher than for the current scenario). But in general, apart from lodging and natural gas industries, the remaining economic activities show a bigger impact on their output. This behavior is explained by the expansion of emissions trading to the entire economy, which lowers the demand for electricity. Therefore, the general equilibrium effects forces a further reduction on the production of electricity and in other EU-ETS industries. Indeed, this leads to greater reductions in $\mathrm{CO}_{2}$ emissions by the electricity generation $(-29.0 \%,-37.5 \%)$ than in the preceding scenario, although alleviating the pressure on emissions from the other ETS industries.

Figure 5. Impact on output and emissions by industry in the expanded scenario

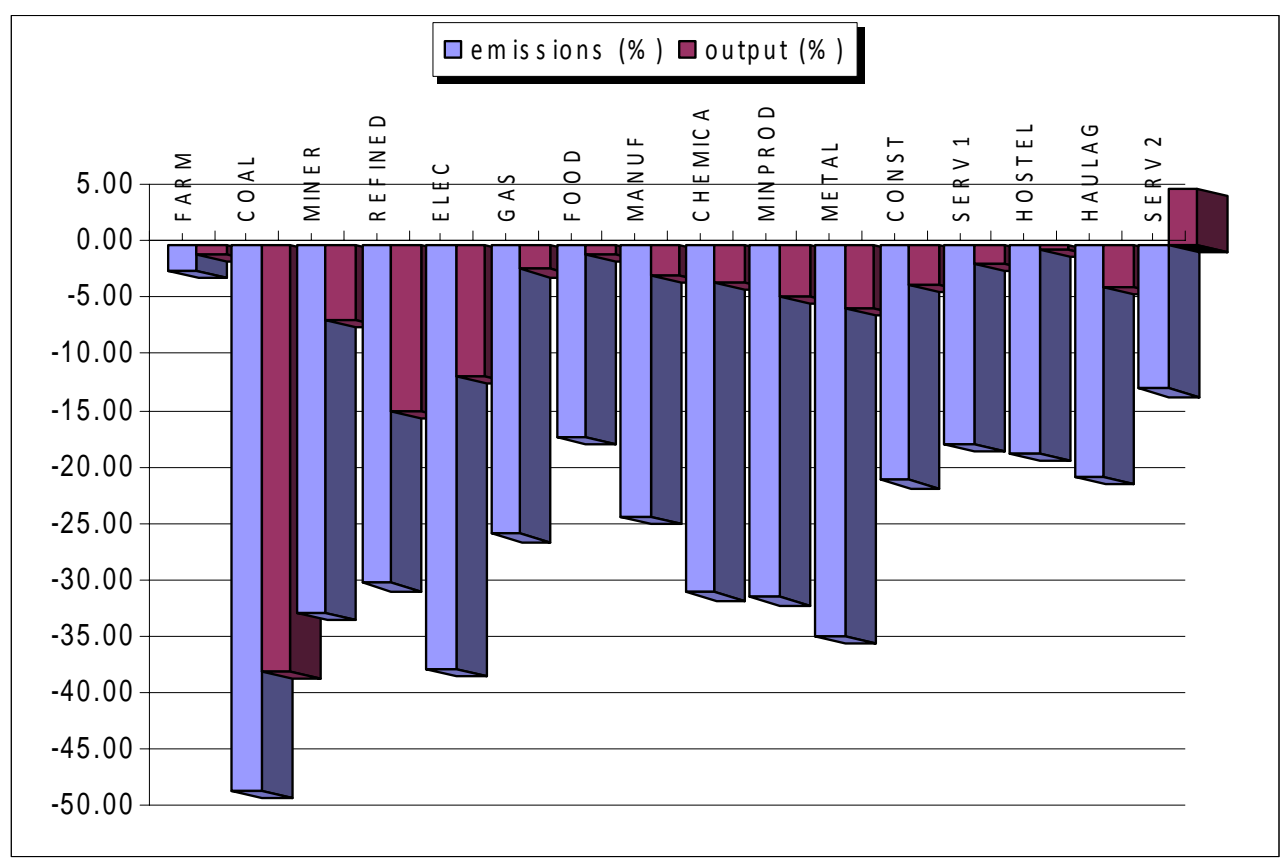

Source: The authors 
Table 3. Impact by industry (\%) of each scenario on economic activity

\begin{tabular}{|l|r|r|r|r|}
\hline & $\begin{array}{r}\text { Current } \\
(1)\end{array}$ & $\begin{array}{r}\text { Expanded } \\
(2)\end{array}$ & \multicolumn{1}{c|}{$\begin{array}{c}\text { difference } \\
(2)-(1)\end{array}$} & $\begin{array}{c}\text { variation } \\
{[(2)-(1)] /(1)}\end{array}$ \\
\hline AGRICULTURE (FARM) & 0.0 & -0.9 & -0.9 & $-42.8 \%$ \\
\hline COAL & -26.4 & -37.7 & -11.3 & $-294.1 \%$ \\
\hline MINING (MINER) & -1.7 & -6.7 & -5.0 & $-101.4 \%$ \\
\hline OIL (REFINED) & -7.3 & -14.7 & -7.4 & $-10.5 \%$ \\
\hline ELECTRICITY (ELEC) & -10.5 & -11.6 & -1.1 & $132.8 \%$ \\
\hline GAS & 6.7 & -2.2 & -8.9 & $-200.0 \%$ \\
\hline FOOD & -0.3 & -0.9 & -0.6 & $-350.0 \%$ \\
\hline MANUFACTURING (MANUF) & -0.6 & -2.7 & -2.1 & $-277.8 \%$ \\
\hline CHEMICAL (CHEMIC) & -0.9 & -3.4 & -2.5 & $-155.6 \%$ \\
\hline MINING PRODUCTION (MINPROD) & -1.8 & -4.6 & -2.8 & $-211.1 \%$ \\
\hline METAL & -1.8 & -5.6 & -3.8 & $-157.1 \%$ \\
\hline CONSTRUCTION (CONST) & -1.4 & -3.6 & -2.2 & $-112.5 \%$ \\
\hline SERVICES 1 (SERV1) & -0.8 & -1.7 & -0.9 & $0.0 \%$ \\
\hline HOTEL-RESTAURANTS (HOSTEL) & -0.4 & -0.4 & 0.0 & $-362.5 \%$ \\
\hline TRANSPORT (HAULAG) & -0.8 & -3.7 & -2.9 & $533.3 \%$ \\
\hline SERVICES 2 (SERV2) & -1.2 & 5.2 & 6.4 & \\
\hline
\end{tabular}

Source: The authors

Tables 3 and 4 compare the impact by industry on activity and $\mathrm{CO}_{2}$ emissions for the different sectors under the two scenarios when the CGE and electricity industry models are integrated. These data are indicative, firstly, of the relevance and variation of the distributive and environmental effects of each alternative. Note that the introduction of detailed electricity industry modeling leads not only to substantial changes in this industry's reactions to the simulated policies and alternatives, but also heavily impacts the general equilibrium with other industries (through the above-mentioned changes in electric power prices and inter-industry supply and demand). 
Table 4. Impact by industry (\%) of each scenario on $\mathrm{CO}_{2}$ emissions

\begin{tabular}{|l|r|r|r|r|}
\hline & \multicolumn{1}{|c|}{$\begin{array}{c}\text { Current } \\
(1)\end{array}$} & \multicolumn{1}{c|}{$\begin{array}{c}\text { Expanded } \\
(2)\end{array}$} & $\begin{array}{c}\text { difference } \\
(2)-(1)\end{array}$ & $\begin{array}{c}\text { variation } \\
{[(2)-(1)] /(1)}\end{array}$ \\
\hline AGRICULTURE (FARM) & -2.3 & -2.3 & 0.1 & $3.0 \%$ \\
\hline COAL & -28.5 & -48.3 & -19.8 & $-69.3 \%$ \\
\hline MINING (MINER) & -7.1 & -32.6 & -25.5 & $-358.2 \%$ \\
\hline OIL (REFINED) & -39.8 & -29.9 & 9.8 & $24.7 \%$ \\
\hline ELECTRICITY (ELEC) & -24.8 & -37.5 & -12.7 & $-51.2 \%$ \\
\hline GAS & 3.6 & -25.6 & -29.2 & $805.0 \%$ \\
\hline FOOD & -2.8 & -17.0 & -14.2 & $-503.6 \%$ \\
\hline MANUFACTURING (MANUF) & -6.9 & -24.1 & -17.2 & $-251.2 \%$ \\
\hline CHEMICAL (CHEMIC) & -5.9 & -30.8 & -24.9 & $-419.9 \%$ \\
\hline MINING PRODUCTION (MINPROD) & -53.8 & -31.2 & 22.6 & $42.0 \%$ \\
\hline METAL & -54.5 & -34.6 & 19.9 & $36.5 \%$ \\
\hline CONSTRUCTION (CONST) & -3.6 & -20.8 & -17.2 & $-477.3 \%$ \\
\hline SERVICES 1 (SERV1) & -3.5 & -17.6 & -14.1 & $-402.0 \%$ \\
\hline HOTEL-RESTAURANTS (HOSTEL) & -3.2 & -18.5 & -15.3 & $-479.0 \%$ \\
\hline TRANSPORT (HAULAG) & -2.3 & -20.6 & -18.3 & $-797.8 \%$ \\
\hline SERVICES 2 (SERV2) & -3.7 & -12.8 & -9.1 & $-244.7 \%$ \\
\hline
\end{tabular}

Source: The authors

\section{CONCLUSIONS}

The reduction of greenhouse gas emissions is one of the present priorities of the European Union's energy and environmental policies. The European Commission promoted the creation of a European GHG emissions trading scheme as a cost-efficient mechanism to achieve this aim. The scheme, which became operational in 2005, includes only a limited number of industries (which account for around $50 \%$ of emissions of these gases) and entails largely cost-free allocation of allowances for participants. The suitability of some of the characteristics of this market has been called into question: partial coverage of emissions, intertemporal limitations to trading, cost-free allocation of allowances. The 
directive that will regulate the European market after 2012 introduces significant changes in both the environmental targets and the allocation procedure.

In this context, the present paper simulates the preceding changes changes in Spain, calculating the economic and distributive impact of two hypotheses regarding the scope of the EU ETS in terms of industries affected. We feel that Spain, in fact, is an ideal country for this type of simulations. On the one hand, the economic and distributive impact of the reductions needed to comply with international targets are expected to be highly significant. Moreover, the necessary inclusion of certain industries (such as transport) in the emissions reduction effort calls for an empirical study of these questions.

To date, these issues have been addressed primarily by simulations with computable general equilibrium models, which can accommodate all possible interactions (such as changes in the demand for goods or services or substitutions of one fuel for another) and furnish information on a country's welfare or output. This approach poses certain problems, however, for it is unable to reflect the markets most directly affected by such policies, namely energy markets, in sufficient detail. This calls for industryspecific models, in which the variety of technological options and pricing mechanisms can be suitably represented.

This paper introduces a combination of the two methodologies, thereby integrating the advantages of general equilibrium models and the detail of specific models, in this case for the electricity industry, by soft-linking and iterating the two until they converge. The approach delivers both macroeconomic (GDP, welfare, prices) estimates and the distributive profile (by industry) resulting from the simulations. A comparison of the outputs obtained with the integrated approach to the computable general equilibrium model findings reveals the greater explanatory capacity of the former.

Integrating the two approaches to study the European emissions trading scheme in Spain yielded interesting results. Firstly, the emissions reduction policies are observed to induce a rise in electric power prices in Spain, along with a slight decline in GDP and welfare, and a minor increase in prices. At the same time, when the number of industries subject to the European scheme is expanded, the negative impact is observed to decline not only overall, but also by industry. Lastly, the aptness of integrating the 
two types of models to analyze these issues has been clearly shown. On the one hand, the impact on the electricity industry appears to be more realistic, with the higher prices that would be expected given the marginalist nature of the Spanish electric power market. And on the other, impact distribution by industry also changes substantially under the integrated approach.

The relevance of this type of analysis and the findings is obvious to defining a suitable policy not only in Europe, but also in countries such as the United States and Australia, where systems similar to the EU ETS are being designed to control $\mathrm{CO}_{2}$ emissions The expansion of emissions trading schemes to non-manufacturing industries may also yield significant benefits in these countries. 


\section{REFERENCES}

Ballard, C., Shoven, J., Whalley, J. (1985). “General Equilibrium Computations of the Marginal Welfare Costs of Taxes in the United States”. American Economic Review 75(1): 128-138.

Böhringer, C., Ferris, M., Rutherford, T. (1997). “Alternative $\mathrm{CO}_{2}$ Abatement Strategies for the European Union”. In Proost, S., Brader, J. (Eds.), Climate Change, Transport and Environmental Policy. Cheltenham: Edward Edgar.

Böhringer, C. (1998). “The Synthesis of Bottom-up and Top-down in Energy Policy Modelling”. Energy Economics 20(3): 283-291.

Böhringer, C., Hoffmann, T., Lange, A., Löschel, A., Moslener, U. (2005). “Assessing Emissions Regulation in Europe: An Interactive Simulation Approach”. Energy Journal, 26: 1-22.

Böhringer, C., Löschel, A. (2006). "Promoting Renewable Energy in Europe: a Hybrid Computable General Equilibrium Approach”. Energy Journal, Special Issue: 135-150.

Böhringer, C., Rutherford, T. (2007). "Integrating Bottom-up into Top-down: a Mixed Complementary Approach”, Discussion Paper No. 06-007, Center for European Economic Research ZEW, Germany.

Böhringer, C., Rutherford, T. (2008). “Combining Bottom-up and Top-down”. Energy Economics 30: 574-596.

Bosetti, V., Carraro, C., Galeotti, M., Massetti, E., Tavoni, M. (2006). "WITCH: A World Induced Technical Change Hybrid Model”. Energy Journal, Special Issue: 13-38.

Edmonds, J., Wilson, T., Wise, M., Weyant, J. (2006). "Electrification of the Economy and $\mathrm{CO}_{2}$ emissions mitigation”. Journal of Environmental Economics and Policy Studies 7: 175-203.

Ellerman, A., Joskow, P. (2008). The European Union's Emissions Trading System in Perspective. Pew Center for Global Climate Change.

European Commission (2009). Directive of the European Parliament and the Council amending Directive 2003/87/EC so as to improve and extend the greenhouse gas emission allowance trading scheme of the Community. PE-CONS 3737/08.

Fernandez, M., Manrique, C. (2004). "La Matriz de Contabilidad Nacional: un Método Alternativo de Presentación de las Cuentas Nacionales”. Revista Asturiana de Economía 37: 85-105.

Ghersi, F., Hourcade, J. (2006). "Macroeconomic Consistency Issues in E3 modeling: The Continued Fable of the Elephant and the Rabbit”. Energy Journal, Special Issue: 39-61.

Hogan, W., Manne, S. (1977). "Energy-Economy Interactions: The Fable of the Elephant and the Rabbit?” In Hitch, C. (ed.). Modeling Energy-economy Interactions: Five Approaches: 247-277. Washington D.C.: Resources for the Future.

Hourcade, J., Jaccard, M., Bataille, C., Ghersi, F. (2006). "Hybrid Modeling: New Answers to Old Challenges”. Energy Journal, Special Issue:1-11. 
IEA (1998). Energy Statistics of OECD Countries. 1995-1996. Paris: International Energy Agency.

INE (2002a). Contabilidad Nacional de España. Base 1995. Serie Contable 1995-2000. Marco Inputoutput 1995-1996-1997, Madrid: Instituto Nacional de Estadística.

INE (2002b). Estadísticas de Medio Ambiente. Cuentas Ambientales. Madrid: Instituto Nacional de Estadística.

Labandeira, X., Labeaga, J., Rodriguez, M. (2009). “An integrated Economic and Distributional Analysis of Energy Policies”. Energy Policy, forthcoming.

Labeaga, J., Sanz, J. (2001). ”Oferta de trabajo y fiscalidad en España. Hechos recientes y tendencias tras el nuevo IRPF”. Papeles de Economía Española 87:230-243.

Linares, P., Santos, F., Ventosa, M., Lapiedra, L. (2006). "Estimated Impacts of the European Emissions Trading Scheme Directive and Permit Assignment Methods on the Spanish Electricity Sector”. Energy Journal 27: 79-98

Linares, P., Santos, F., Ventosa, M., Lapiedra, L. (2008a). "Incorporating Oligopoly, $\mathrm{CO}_{2}$ Emissions Trading and Green Certificates into a Power Generation Expansion Model” Automatica 44: 1608-1620.

Linares, P., Santos, F., Pérez-Arriaga, I. (2008b). Scenarios for the Evolution of the Spanish Electricity Sector: Is it on the Right Path towards Sustainability? Energy Policy 36: 4057- 4068.

Manne, A., Mendelsohn, R., Richels, R., (2006). “MERGE: a Model for Evaluating Regional and Global Effects of GHG Reduction Policies”. Energy Policy 23:17-34.

McFarland, J., Reilly, J., Herzog, H. (2004). "Representing Energy Technologies in Top-down Economic Models using Bottom-up Information”. Energy Economics 26: 685- 707

Parry, I., Williams, R., Goulder, L. (1999). "When Can Carbon Abatement Policies Increase Welfare? The Fundamental Role of Distorted Factor Markets". Journal of Environmental Economics and Management 37:52-84.

Pizer, W., Burtraw, D., Harrington, W., Newell, R., Sanchirico, J. (2006). Modeling Economy-wide versus Sectoral Climate Change Policies Using Combined Aggregate-sectoral Models. Energy Journal 27(3): 135-168.

Rivers, N., Jaccard, M. (2005). “Combining Top-down and Bottom-up Approaches To Energy-economy Modeling Using Discrete Choice Methods”. Energy Journal 26: 83-106.

Rutherford, T. (1999). “Applied General Equilibrium Modeling with MPSGE as a GAMS Subsystem: an Overview of the Modeling Framework and Syntax”. Computational Economics 14:1-46.

Schäfer, A., Jacoby, H. (2006). "Experiments with a Hybrid CGE-MARKAL Model”. Energy Journal, Special Issue: 171-177.

Shoven, J., Whalley, J. (1992). Applying general equilibrium. Cambridge: Cambridge University Press. 
Sue Wing, I. (2006). "The Synthesis of Bottom-up and Top-down Approaches to Climate Policy Modeling: electric Power Technologies and the Cost of Limiting U.S. $\mathrm{CO}_{2}$ Emissions”. Energy Policy 34: 847-3869.

Sue Wing, I. (2008). "The synthesis of Bottom-up and Top-down Approaches to Climate Policy Modeling: Electric Power Technology Detail in a Social Accounting Framework”. Energy Economics 30: 547-573.

Vives, X. (1999). Oligopoly Pricing. Cambridge: The MIT Press. 


\section{ÚLTIMOS DOCUMENTOS DE TRABAJO}

2009-29: “An Integrated Approach to Simulate the Impacts of Carbon Emissions Trading Schemes”, Xavier Labandeira, Pedro Linares y Miguel Rodríguez.

2009-28: "Disability, Capacity for Work and the Business Cycle: An International Perspective”, HugoBenítez-Silva, Richard Disney y Sergi Jiménez-Martín.

2009-27: "Infant mortality, income and adult stature in Spain”, Mariano Bosch, Carlos Bozzoli y Climent Quintana-Domeque.

2009-26: “Immigration and Social Security in Spain”, Clara I. Gonzalez, J. IgnacioConde-Ruiz y Michele Boldrin.

2009-25: “Business Cycle Effects on Labour Force Transitions for Older People in Spain”, Sergi JiménezMartín y Judit Vall Castello.

2009-24: “Inequality of Opportunity and Growth”, Gustavo A. Marrero y Juan G. Rodríguez.

2009-23: “A Characterization Of The Judicial System In Spain: Analysis With Formalism Indices”, Juan S. Mora.

2009-22: “Anthropometry and Socioeconomics in the Couple: Evidence from the PSID”, Sonia Oreffice y Climent Quintana-Domeque.

2009-21: “Stimulating Graduates' Research-Oriented Careers: Does Academic Research Matter?”, Mauro Sylos Labini y Natalia Zinovyeva.

2009-20: "Papers or Patents: Channels of University Effect on Regional Innovation”, Robin Cowan y Natalia Zinovyeva.

2009-19: “Innovation, Tangible and Intangible Investments and the Value of Spanish Firms”, Aitor Lacuesta, Omar Licandro, Teresa Molina y Luis A. Puch.

2009-18: “Estimation of Elasticity Price of Electricity with Incomplete Information”, Xavier Labandeira, José M. Labeaga y Xiral López-Otero.

2009-17: "MEDEA: A DSGE Model for the Spanish Economy", Pablo Burriel, Jesús FernándezVillaverde y Juan F. Rubio-Ramírez.

2009-16: "Greenhouse gases emissions, growth and the energy mix in Europe: A dynamic panel data approach”, Gustavo A. Marrero.

2009-15: "Impact of the Rise in immigrant unemployment on public finances", Pablo Vazquez, Mario Alloza, Raquel Vegas y Stefano Bertozzi.

2009-14: 'Responding to Financial Pressures. The Effect of Managed Care on Hospitals' Provision of Charity Care”, Núria Mas.

2009-13: “Domestic Transport Cost Reductions and Firms’ Export Behaviour”, Pedro Albarran, Raquel Carrasco y Adelheid Holl.

2009-12: “Compatibility with Firm Dominance”, María Fernanda Viecens.

2009-11: “Pricing Strategies in Two-Sided Platforms: The Role of Sellers’ Competition”, María Fernanda Viecens.

2009-10: “Scheduled Service Versus Personal Transportation: the Role of Distance”, Volodymyr Bilotkach, Xavier Fageda y Ricardo Flores-Fillol.

2009-09: “Social Preferences and Strategic Uncertainty: An Experiment on Markets and Contracts”, Antonio Cabrales, Rafaele Miniaci, Marco Piovesan y Giovanni Ponti.

2009-08: "Hidden Information, Bargaining Power and Efficiency: An Experiment”, Antonio Cabrales, Gary Charness y Marie Claire Villeval.

2009-07: "Democracy and the curse of natural resources", Antonio Cabrales y Esther Hauk.

2009-06: "Social Interactions and Spillovers: Incentives,Segregation and Topology", Antonio Cabrales, Antoni Calvó-Armengol e Yves Zenou.

2009-05: “Chance Constrained Programming with one Discrete Random Variable in Each Constraint”,Emilio Cerdá Tena y Julio Moreno Lorente.

2009-04: "Economic Value of Weather Forecasting Systems Information: A Risk Aversion Approach", Emilio Cerdá Tena y Sonia Quiroga Gómez.

2009-03: "Population Ageing, Inequality and the Political Economy of Public Education", Francisco Martínez-Mora.

2009-02: "Real Wages over the Business Cycle: OECD Evidence from the Time and Frequency Domains", Julian Messina, Chiara Strozzi y Jarkko Turunen.

2009-01: “The Determinants Of Misreporting Weight And Height: The Role Of Social Norms”, Joan Gil y Toni Mora.

2008-42: "Social Security Incentives, Exit from the Workforce and Entry of the Young”, Michele Boldrin, Pilar García-Gómez y Sergi Jiménez-Martín. 